\title{
Charge-to-mass ratio of individual blowing-snow particles
}

\author{
D. S. Schmidt, J. D. Dent, ${ }^{1}$ R. A. Schmidt ${ }^{2}$ \\ ${ }^{1}$ Department of Civil Engineering, Montana State University, Bozeman, MT 59717, U.S.A. \\ ${ }^{2}$ Rocky Mountain Forest and Range Experiment Station, U.S. Forest Service, Laramie, Wr 82070, U.S.A.
}

\begin{abstract}
Determining the electrostatic force acting on saltating snow particles requires knowledge of the electric field in the saltation region and the charge on the particle. To date, measurements of average charge-to-mass ratios for blowing-snow samples have been made but Schmidt and Schmidt (1993) have indicated these may underestimate charge-to-mass ratios for individual particles due to a mixture of positive and negative charge in the samples. This paper reports on measurements of charge-to-mass ratio for individual blowing-snow particles during a moderate blowing-snow storm in southwestern Wyoming. We measured charge-to-mass ratios as large as $-208 \mu \mathrm{C} \mathrm{kg}^{-1}$, significantly higher than the $-10 \mu \mathrm{C} \mathrm{kg}^{-1}$ measured by Latham and Montagne (1970) and $-50 \mu \mathrm{C} \mathrm{kg}^{-1}$ measured by Wishart (1970). This large charge-to-mass ratio was accompanied by a distribution of positive and negative charge on the particles, supporting the conclusions of Schmidt and Schmidt (1993).
\end{abstract}

\section{INTRODUCTION}

Wind is an incredibly powerful force capable of moving vast quantities of snow during blizzards. Deposition of windblown snow forms large drifts that hamper winter travel. In mountainous regions, cornices and wind-deposited snow in the lee of ridges trigger avalanches that damage structures and transport systems. Effective control of these natural phenomena requires a better understanding of the physical processes in blowing snow.

Wind transports snow by three mechanisms. Particles roll along the surface in a process termed "creep". This mechanism occurs in light winds and accounts for very little transport. Strong winds eject particles from the surface in a mode of transport called "saltation". Particles in saltation bounce along the surface, rebounding to heights typically within $10 \mathrm{~cm}$ of the surface. Much of transport during blowing-snow storms moves in saltation. In the third transport mode, known as "suspension", particles travel without impact, at heights that may extend several hundred meters in polar storms. Saltating particles are the source for suspended transport, therefore understanding saltation is essential to controlling blowing snow.

This paper re-examines the magnitude of the electrostatic charges that develop on saltating snow particles. Most laboratory and field studies of saltation have ignored electrostatic forces. In the few studies directed toward measuring particle charge, we believe the methods underestimate magnitudes. The remainder of this introduction presents a brief review of research on the electrostatic force and why previous experiments might have underestimated particle charge-to-mass ratios. The following sections describe the equations, apparatus, field procedures and results of our experiment. Our thoughts on the implications of the results on the saltation process are set out in the discussion.

\section{The saltation process}

Saltating snow particles rebound from elastic impact with the surface, following long, low trajectories in response to forces of fluid drag and gravitation. Whether it be snow particles in the atmosphere or glass beads in a wind tunnel, the equations that describe the motion of saltating particles are the same. White and Schultz (1977) used a high-speed camera to photograph trajectories of saltating glass spheres in a wind tunnel. They found trajectories higher and longer than those predicted from theoretical equations involving only fluid drag and the gravitational force. This indicated the presence of an additional lift force. Lift develops if the particle spins and White and Schultz (1977) showed good agreement with the observed trajectories by adding the Magnus lift to the theoretical equations. To produce consistent trajectories from the addition of Magnus effect alone, White and Schultz (1977) assumed spin rates in the range 100-300 rev s$^{-1}$. Another force that could explain the additional lift on saltating particles is the electrostatic force that results from friction between the moving particles and the surface.

\section{Electrification of blowing snow}

A charged particle, in an electric field, is subject to an electrostatic force. The magnitude of the force is equal to the product of the electric field and the charge on the particle. The force acts along the electric field vector in the direction determined by the sign of the particle charge. Schmidt and Schmidt (1993) reviewed research on the mechanisms that produce charge separation in saltating snow. These mechanisms usually produce moving particles that are negatively charged, while surface particles become positive. Blizzard measurements (Schmidt, 1994) confirmed the predictions by Schmidt and Dent (1993) that electric fields near the sur- 
face in saltating snow are several orders of magnitude larger than the fair-weather field $\left(100 \mathrm{~V} \mathrm{~m}^{-1}\right)$.

Wishart (1970) and Latham and Montagne (1970) reported measurements of average charge-to-mass ratios in which samples of drifting particles were collected. Schmidt and Schmidt (1993) also reported charge and mass for blizzard particles collected in a portable Faraday cage with simultaneous wind-speed measurements. Reductions, and actual reversal, in sign of measured charge during wind gusts has strongly suggested that eroded surface particles of opposite sign were mixing with moving particles. This would indicate an average particle charge-to-mass ratio determined by measuring the charge on blowing-snow samples and dividing by the sample mass would underestimate charge-to-mass ratios of the individual snow particles.

\section{Experiment outline}

The purpose of the experiment presented here was to measure the charge-to- mass ratio on an individual blowing-snow particle. In his famous experiment, Millikan (1947) measured the charge of single electrons from the motion of oil drops moving in a constant electric field. Camp (1976) used a variation on this technique to determine charge-to-mass ratios for falling snow crystals. Based on their methods, we designed the apparatus and experiment described below to measure the charge on drifting particles. Snow particles were extracted from saltation by a drift trap. Particles that did not impact the trap dropped vertically through a still-air chamber containing a constant horizontal electric field. A detector triggered a photographic imaging system that produced photographs showing particle path and location at known time intervals. Charged particles are deflected horizontally by an amount proportional to their charge, with direction determined by the charge sign. Photographs showing deflection both left and right would confirm our hypothesis that positively and negatively charged particles are transported simultaneously in saltation. The charge-to-mass ratio of the particle can be determined from these images using the equations derived in the next section.

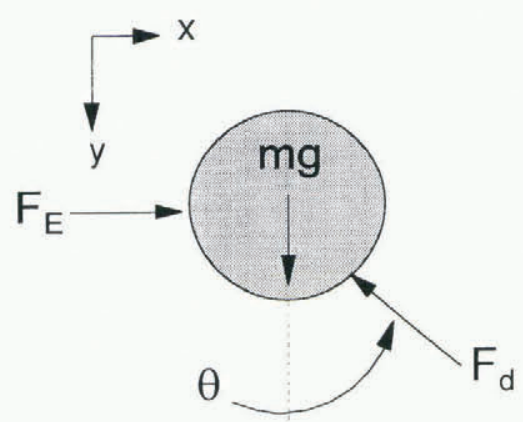

Fig. 1. Free-body diagram of particle falling in air, subject to a constant electrostatic force.

\section{Equations of motion}

A charged particle falling through still air, with a horizontal electric field, is acted upon by the gravitational force, an electrostatic force, and a drag force, due to air resistance, that opposes the particle's motion. If the direction in which the particle travels is defined by an angle $\theta$ with the vertical
(Fig. 1), the equations that describe the particle's motion are

$$
F_{\mathrm{E}}-F_{\mathrm{d}} \sin \theta=m \ddot{x}
$$

and

$$
m g-F_{\mathrm{d}} \cos \theta=m \ddot{y} .
$$

The magnitude of the electrostatic force is $F_{\mathrm{E}}=q E$, where $E$ is the magnitude of the electric field and $q$ is the charge on the particle. For non-spherical particles traveling at low speed, the magnitude of the drag force can be approximated as $F_{\mathrm{d}}=k(3 \pi \mu) d_{\mathrm{N}} v$ (McNown and others, 1951). Here, $k$ denotes the shape factor of the particle, $\mu$ is the dynamic viscosity of air, $d_{\mathrm{N}}$ is the particle's nominal diameter and $v$ is the velocity of the particle.

If we assume the particle falls at a terminal velocity $v_{\mathrm{T}}$, then the vertical component of acceleration is zero and the vertical component of the velocity is constant.

Furthermore, if the particle rotates as it falls, it will have a random orientation with time and we can assume the shape factor is the same for all directions.

If we can assume the $x$ component of the velocity is very small when the particle enters the electric field, we can then impose the boundary conditions $\dot{x}=0$, and $x=0$ at time $t=0$.

These two boundary conditions, combined with the assumptions stated above, allow us to solve the equations of motion for the charge-to-mass ratio of the particle.

$$
\left(\frac{q}{m}\right)=\frac{\left(g / v_{\mathrm{T}}\right)^{2} x}{E\left[\left(g / v_{\mathrm{T}}\right) t+\left(\mathrm{e}^{-g t / v_{\mathrm{T}}}-1\right)\right]} .
$$

This equation is the basis of our experimental technique. It evaluates charge-to-mass ratio $q \mathrm{~m}^{-1}$, from measurements of deflection $x$, over time $t$, and the particle's terminal velocity $v_{\mathrm{T}}$. Electric-field strength must be known and gravitational acceleration assumed constant.

Note that the exponential in Equation (3) very quickly dies out and Equation (3) becomes

$$
\left(\frac{q}{m}\right)=\frac{\left(g / v_{\mathrm{T}}\right)^{2} x}{E\left[\left(g / v_{\mathrm{T}}\right) t-1\right]}
$$

which predicts the particle travels with a constant $x$ component of velocity very shortly after entering the region of the electric field.

\section{EXPERIMENTAL METHODS}

\section{Apparatus}

Figure 2 shows the experimental apparatus. Four sub-units comprise the device. The expansion chamber extracts particles from saltation, allowing some to fall into the extension tube, where they accelerate to terminal velocity. Only particles that pass through the detector enter the electric field chamber. The fourth sub-unit, the imaging system, comprises the detector, camera and multi-strobe system. The purpose of this last unit is to illuminate and photograph the particles in the electric field chamber.

The expansion chamber slows air flow and allows particles to settle. Constructed of sheet metal, the expansion chamber maintains the same ratios as the smaller drift trap reported by Mellor (1960). The expansion chamber connects to the rest of the apparatus by means of a rotating cap. This allowed the direction of the nose-cone inlet to be adjusted 

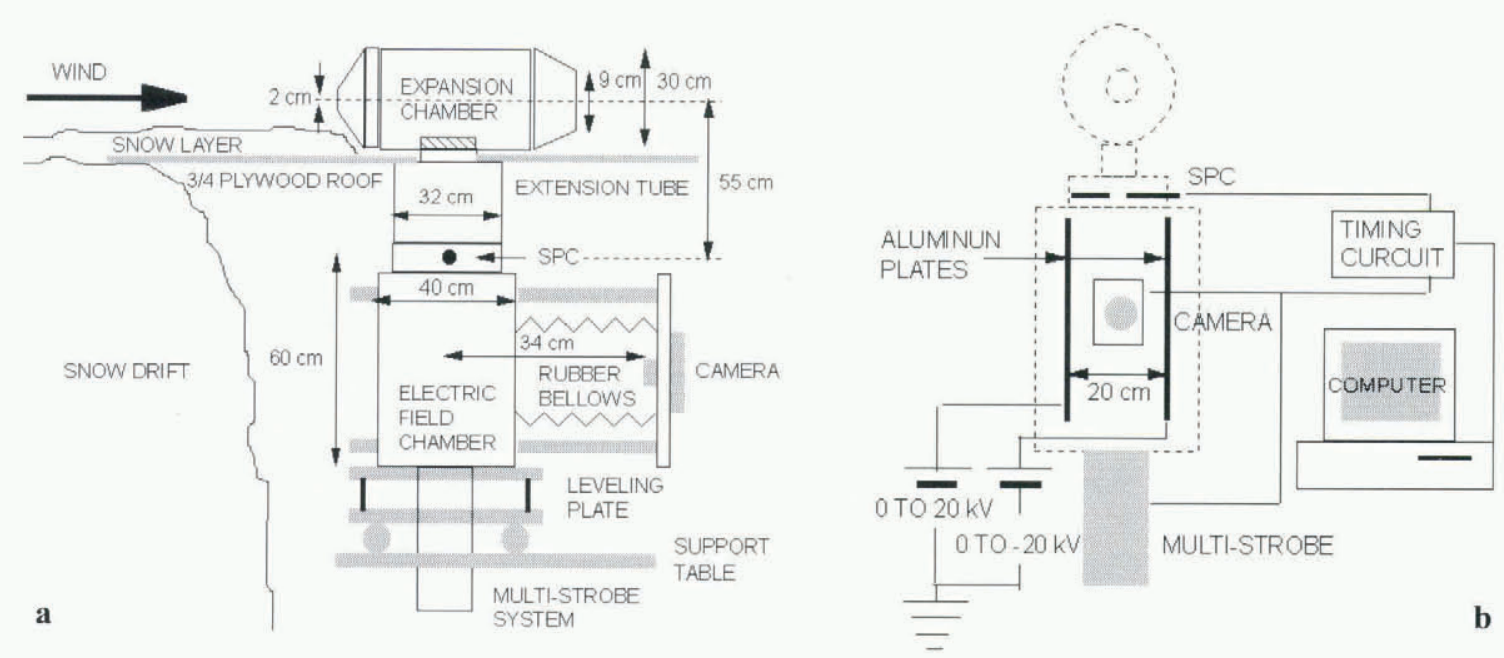

Fig. 2. (a) Apparatus for measuring charge-to-mass ratios of individual blowing-snow particles. (b) Schematic diagram of electric-field chamber and photo-imaging system.

for different wind directions. Once positioned, the cap was fixed in place and sealed by an adhesive fastener (duct tape).

The extension tube allows the particles to reach terminal fall velocity before entering the measurement region. Schmidt (1981) reported size distributions of saltating particles with mean equivalent diameters near $200 \mu \mathrm{m}$. Using a computer iteration-scheme, we determined $24 \mathrm{~cm}$ is required for a $200 \mu \mathrm{m}$ ice sphere to reach a terminal velocity of $53 \mathrm{~cm} \mathrm{~s}^{-1}$. The vertical dimension of the extension tube was $55 \mathrm{~cm}$ in order to insure that most particles attained terminal velocity. The vertical spacing of the images provides a test of this requirement. In order to ensure particles enter the electric field chamber with no $x$ component of velocity, a pair of inverted sheet-metal funnels (truncated cones) act to collimate the particles leading finally to a slit entrance of $2 \mathrm{~cm} \times 0.5 \mathrm{~cm}$ into the electric-field chamber. The entire expansion chamber and collimating system was grounded so that particles coming in contact with any part of the apparatus en route to the electric-field chamber were electrically discharged and not considered in the final analysis.

The electric-field chamber is sealed, providing a still-air region. Two aluminum plates, (Fig. 2b) connected to highvoltage power supplies produce a horizontal electric field across a $20 \mathrm{~cm}$ plate separation. Leveling mechanisms on the bottom corners of the chamber allow leveling to set the electric field perpendicular to gravity. Flat black paint on all interior surfaces of the chamber reduce reflections and black velvet on the chamber wall opposite the camera gives high contrast to the particle images. The high-voltage supplies, adjustable over a range of $0-20 \mathrm{kV}$, provide a variable electric field. Plate voltages measured with a high-voltage probe during the experiment were $+14.93 \mathrm{kV}$ and $-14.60 \mathrm{kV}$, giving an electric field strength $E=147.65 \mathrm{~V} \mathrm{~mm}^{-1}$. Higher values interfered with the particle-detection circuit.

The multi-strobe system (Bird and Jairell, 1989) provides continuous light from a halogen lamp and accurately timed flashes from eight electronic strobes. The result is a photographic image showing a sequence of dots, defining particle location, along a low-intensity white streak on a black background. An adjustable slit (set to $1 \mathrm{~cm}$ ) on a clear plastic window sealed to the bottom of the electric-field chamber confines illumination to a region perpendicular to the plates and centered in the chamber. A small fan on the multistrobe housing removes heat produced by the halogen lamp.
The timing circuit performs two functions. It opens the camera shutter when a particle is detected and triggers the strobe sequence after a delay that allows the particle to move from the detector into the electric-field chamber. Particles are detected by a snow-particle counter (SPC) that senses the particle's shadow in a light beam (Schmidt, 1977). We used a $35 \mathrm{~mm}$ film camera with motor drive, data back and $55 \mathrm{~mm}$, f 1.4 lens to record particle images. A microprocessor controls the timing circuit, allowing programmable time delays. For our experiment, a time delay of $121.6 \mathrm{~ms}$ was set between particle detection and first strobe flash, with $20.0 \mathrm{~ms}$ intervals between each flash.

\section{Field procedure}

The experiment was conducted on 8 January 1996 at the Chimney Park trail head, $96 \mathrm{~km}$ west of Laramie, Wyoming, on Highway 130. Snowplow operators for the Wyoming Highway Department assisted us in forming a $2.1 \mathrm{~m}$ high snow bank at the west end of the trail-head parking lot. Suitable snow cover existed upwind of the site, though no new snow had fallen in several days. A mobile laboratory provided electricity and shelter for computers (as well as investigators). Supporting meteorological data, including wind speed and direction, air temperature and humidity were all measured $1 \mathrm{~m}$ above the surface near the top of the snowbank.

The apparatus was set up just downwind of the snowbank. A roof, level with the top of the snowbank, prevented the apparatus from being drifted in (Fig. 2a). A $20 \mathrm{~cm}$ layer of snow, placed on the roof, smoothed the approach to the inlet of the device. The electric field chamber was leveled and the inlet aligned with the wind.

A length scale was defined for image analysis by suspending a section of metric ruler at the center of the field of view for the first two pictures of each film roll. Four rolls of 36 exposure (ASA 1600) were exposed between 14.00 and $17.00 \mathrm{~h}$, in low-level drifting (no noticeable suspension).

\section{Analysis procedure}

Of the 136 images exposed, 50 showed particle images. We transferred these to compact disk for analysis using computer software. Figure 3 shows an example image from which particle location was digitized. We also digitized the end 
points of the same $100 \mathrm{~mm}$ segment in all images of the ruler to determine a length scale.

Vertical distance between dots, divided by the $20 \mathrm{~ms}$ strobe interval, determined particle-fall velocity. If the particle was at terminal velocity, an average value was computed for $v_{\mathrm{T}}$. Horizontal distance between the first and last dot on the path determined horizontal deflection, $x$. The time, $t$, for this deflection was the product of the $20 \mathrm{~ms}$ strobe interval and the number of intervals between the first and last dot. These measured values of $v_{\mathrm{T}}, x$, and $t$, together with $E=147.65 \mathrm{kV} \mathrm{m}^{-1}$, and $g=9.81 \mathrm{~m} \mathrm{~s}^{-2}$ provided the arguments required to evaluate the charge-to-mass ratio of the particle using Equation (3).

In selecting particle traces for analysis, two criteria were used to ensure particles were traveling at terminal velocity and that measured deflections resulted only from the electrostatic force: (a) at least three strobe dots had to be visible to check for terminal velocity; (b) a trace could not approach or cross other trajectories to be certain the deflection was not influenced by other particles.

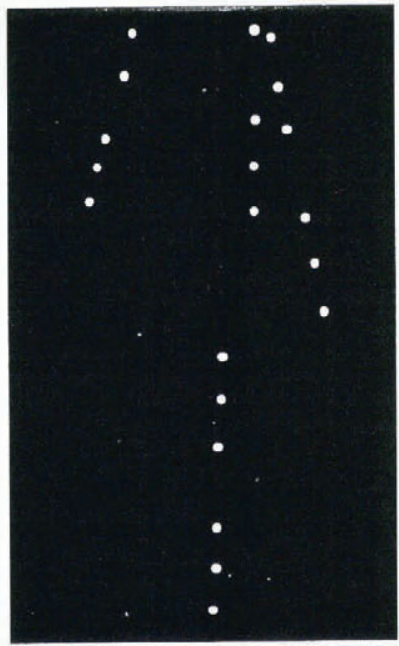

Fig. 3. Image showing trajectories of the first four particles in Table 1. Strobe number five failed to flash throughout the experiment. The image was enhanced and converted to black and white for this figure. Continuous traces were converted to black in the process.

\section{EXPERIMENTAL RESULTS}

The largest variation in measured distance on the eight ruler images was less than $1 \%$; therefore, we used the average of $419 \mathrm{du} \mathrm{mm} \mathrm{m}^{-1}$ to convert coordinates of the strobe dots from digitizer units (du) to actual distance in $\mathrm{mm}$. Eleven traces met the criteria for analysis. Table 1 lists measurements and computed charge-to-mass ratios for these particles. Data for the four particles in Figure 3 are listed first. Wind speed decreased from $10 \mathrm{~m} \mathrm{~s}^{-1}$ at the beginning of sampling to $5 \mathrm{~m} \mathrm{~s}^{-1}$ near the end. Temperature decreased from $+1^{\circ}$ to $-2{ }^{\circ} \mathrm{C}$, with relative humidity dropping from $93 \%$ during peak drifting to $70 \%$ as winds decreased.

\section{Error analysis}

We estimated the errors for computed charge-to-mass ratios in Table 1 from the errors in each argument of the computation. A worst-case analysis for a particle with $500 \mathrm{~mm} \mathrm{~s}^{-1}$ fall velocity, deflected $15 \mathrm{~mm}$ in $100 \mathrm{~ms}$ by an electric field
Table 1. Measurements and computed charge-to-mass ratios

\begin{tabular}{rrrrrr}
\hline $\begin{array}{c}\text { Particle } \\
\text { number }\end{array}$ & $v_{\mathrm{T}}$ & $\begin{array}{c}\text { Std dev } \\
v_{\mathrm{T}}\end{array}$ & \multicolumn{1}{c}{$t$} & $q \mathrm{~m}^{\prime}$ \\
& & & & & \\
& $\mathrm{mm}^{-1}$ & $\mathrm{~mm}^{-1}$ & $\mathrm{~mm}$ & $\mathrm{~ms}$ & $\mu \mathrm{C} \mathrm{kg}^{-1}$ \\
& & & & & \\
\hline 1 & 425.18 & 5.35 & -14.53 & 100 & -37 \\
2 & 534.69 & 19.56 & 0.38 & 100 & 1 \\
3 & 557.93 & 18.32 & 19.12 & 120 & 33 \\
4 & 534.61 & 0.00 & -1.15 & 40 & -12 \\
5 & 510.13 & 0.13 & 13.74 & 100 & 32 \\
6 & 338.17 & 10.06 & 11.91 & 120 & 27 \\
7 & 571.38 & 18.24 & 22.61 & 80 & 72 \\
8 & 593.55 & 11.86 & -11.91 & 120 & -20 \\
9 & 491.87 & 12.84 & -26.27 & 100 & -63 \\
10 & 438.78 & 14.34 & -18.63 & 40 & -208 \\
11 & 627.45 & 7.09 & -10.08 & 40 & -106 \\
& & & & & \\
\hline
\end{tabular}

of $148 \mathrm{kV} \mathrm{mm}^{-1}$ gives a maximum error of $4 \%$ in $\mathrm{qm}^{-1}$, equal to $1.5 \mu \mathrm{C} \mathrm{kg}^{-1}$. Per-cent error increased as deflections decreased.

\section{DISGUSSION}

The derivation of Equation (3) depends on two critical assumptions: (a) particles fall at terminal velocity; (b) the shape factor (drag coefficient) is the same in all directions. Very consistent vertical distances between dots on each trace strongly support both assumptions. Measured variations in fall velocity were random for all traces and within the uncertainty of the measurement. We saw no trace oscillations characteristic of particles falling with a preferred orientation (e.g. as reported for plate snow crystals). The ratio of longest axis to perpendicular axis averaged 1.49 for saltating snow photographed by Schmidt (1981). Saltation impacts and non-uniform instantaneous drag on such particles will cause rotations that continue after particles enter our apparatus. These rotations should yield an average shape factor approximately constant with respect to direction.

Average charge-to-mass ratios near $-10 \mu \mathrm{C} \mathrm{kg}^{-1}$ have been reported for blowing snow in the semi-arid climates of Montana (Latham and Montagne, 1970) and Wyoming, USA (Schmidt, 1994). Ratios as large as $-50 \mu \mathrm{C} \mathrm{kg}^{-1}$ were measured in Antarctica by Wishart (1970). Many particles we evaluated had charge-to-mass ratios significantly higher than average charge-to-mass ratios previously measured in semiarid climates. The largest individual ratio was $-208 \mu \mathrm{C} \mathrm{kg}^{-1}$, four times the largest average ratio previously reported. Although knowledge of the electrification process is incomplete, we speculate that even larger ratios occur in more intense drifting. Schmidt (1994) demonstrated that a chargeto-mass ratio of $-10 \mu \mathrm{C} \mathrm{kg}^{-1}$ has a significant influence on computed saltation trajectories. For particles with negative charge saltating on a snow surface with net positive charge, the electrostatic force (attraction) shortens trajectories. On the other hand, particles with positive charge, eroded from the surface during wind gust, should have longer trajectories with higher rebounds. These particles will have increased probability of suspension by turbulence. Based on the results reported here, questions of charge distribution with height, and charge decay-rate for particles freshly de- 
tached from the surface, become critical next steps in our research.

\section{CONGLUSIONS}

Although the apparatus is necessarily large, modification of Millikan's (1947) technique can provide charge-to-mass ratios for individual saltating particles.

Blowing-snow particles with opposite charge sign co-exist in saltation. This fact must be considered when measurements of charge-to-mass ratios are made by averaging the charge over a sample mass.

Even for the low-intensity drifting in this experiment, particle charge-to-mass ratios were significantly larger than the maximum $q \mathrm{~m}^{-1}$ previously estimated by trapping weighable quantities of drifting particles in a Faraday cage.

\section{REFERENCES}

Bird, K. G. and R. L. Jairell. 1989. Sequential flash for photographing trajectories of saltating snow particles. Proc. West. Snow Conf., 57th Annual Meeting, 18-20 April 1989, Fort Collins, Colorado, 130-133.

Camp, P. R. 1976. Charge, morphology, and $\mathrm{pH}$ of natural snow. J. Geophys. Res., 81(9), 1589-1592.
Latham, J. and J. Montagne. 1970. The possible importance of electrical forces in the development of snow cornices. F. Glaciol., 9 (57), 375-384.

McNown, J. S., J. Malaika and R. Pramanik. 1951. Particle shape and settling velocity. In Fourth Meeting of the International Association for Hydraulic Research, Bombay, India. Transactions. Delft, W. D. Meiwema, 511-522.

Mellor, M. 1960. Gauging Antarctic drift snow. In Antarctic Meteorology. Proceedings of the Symposium ..., Melbourne ... 1959, Oxford, etc., Pergamon Press, 347-359.

Millikan, R.-A. 1947. Electrons, protons, photons, neutrons, mesotrons, and cosmic rays. Second edition. Chicago, IL, University of Chicago Press.

Schmidt, R. A. 1977. A system that measures blowing snow. U.S. For. Serv. Res. Pap. RM-194.

Schmidt, R. A. 1981. Estimates of threshold windspeed from particle sizes in blowing snow. Cold Reg. Sci. Technol., 4(3), 187-193.

Schmidt, S. 1994. Measurements of the electric field gradient in a blizzard. In ISSW'94. International Snow Science Workshop, 30 October-3 November 19.94, Snowbird, Utah. Proceedings. Snowbird, UT, P.O. Box 49, 197-202.

Schmidt, S. and J. D. Dent. 1993. A theoretical prediction of the effects of electrostatic forces on saltating snow particles. Ann. Glaciol., 18, 234-238.

Schmidt, S. and R. A. Schmidt. 1993. The sign of electrostatic charge on drifting snow. In Armstrong, R., ed. ISSW'92. International Snow Science Workshop, 4- 8 October 1992, Breckenridge, Colorado. Proceedings. Denver, CO, Avalanche Information Center, 351-360.

White, B. and J. Schultz. 1977. Magnus effects in saltation. F. Fluid Mech., $81(3), 495-512$.

Wishart, E. R. 1970. Electrification of Antarctic drifting snow. International Association of Scientific Hydrology Publication 86 (Symposium at Hanover, New Hampshire, 1968-Antarctic Glaciological Exploration (ISAGE)), 316-324. 